\title{
Doppler prediction of adverse perinatal outcome in intrauterine growth restriction
}

\author{
Nina Mahale ${ }^{1}$, Bandana Khanal ${ }^{1}$, Ajit Mahale ${ }^{2 *}$, Merwyn Fernandes ${ }^{2}$, \\ Pallavi Rao ${ }^{2}$, Chanabasappa Chavadi ${ }^{2}$
}

\footnotetext{
${ }^{1}$ Department of Obstetrics \& Gynecology, KMC Mangalore Manipal University, Mangalore, Karnataka, India

${ }^{2}$ Department of Radiodiagnosis KMC Mangalore Manipal University, Mangalore, Karnataka, India
}

Received: 28 December 2014

Accepted: 19 January 2015

\author{
*Correspondence: \\ Dr. Ajit Mahale, \\ E-mail: ajitmahale137@gmail.com
}

Copyright: (C) the author(s), publisher and licensee Medip Academy. This is an open-access article distributed under the terms of the Creative Commons Attribution Non-Commercial License, which permits unrestricted non-commercial use, distribution, and reproduction in any medium, provided the original work is properly cited.

\begin{abstract}
Background: Objective of current study was to determine and compare the diagnostic performance of Doppler ultrasonography of the fetal Middle Cerebral Artery (MCA) and Umbilical Artery (UA) for prediction of adverse perinatal outcome in suspected intrauterine growth restriction (IUGR).

Methods: Fifty singleton pregnancies in third trimester of pregnancy with suspected intrauterine growth restriction were examined with Doppler ultrasonography of fetal MCA and UA.

Results: Twenty patients of the fifty included patients had at least one major or minor adverse outcome. Major adverse outcome included perinatal deaths which included both intrauterine deaths and early neonatal deaths, hypoxic ischemic encephalopathy, intraventricular hemorrhage, periventricular leukomalacia, pulmonary hemorrhage, necrotizing enterocolitis and septicemia. Minor outcomes included cesarean section for fetal distress, Apgar score below 7 at 5 minutes and admission to Neonatal Intensive Care Unit (NICU) for treatment. MCA PI is the most sensitive $(90 \%)$ index in predicting any adverse perinatal outcome i.e. including both major and minor outcomes, Positive Predictive Value (PPV) and specificity being greatest for MCA/UA PI (96.6\%, 93.7\%). For the major adverse outcome most sensitive (86.6\%) most specific (91.4\%) and with highest PPV (81.2\%) and NPV (94.1\%), is $\mathrm{MCA} / \mathrm{UA}$ PI. Ratio of MCA/UAPI is more sensitive (90\%) than PI of both the arteries alone for overall prediction of adverse perinatal outcome.

Conclusions: Thus we conclude that the Doppler studies of the multiple vessels in the fetoplacental unit can help in the monitoring of the compromised fetus and can help us predicting neonatal morbidity. This may be helpful in determining the optimal time of deliveries in pregnancies complicated by IUGR.
\end{abstract}

Keywords: Adverse outcome, Doppler, Pregnancy IUGR

\section{INTRODUCTION}

Disturbance of normal fetal growth can result in abnormal weight, body mass or body proportion at birth. Growth is a dynamic process, and only the comparison of absolute measurements with gestational age reference ranges allows the detection of discrepancies between expected and actual growth. The landmark observations of Lubchenco and colleagues in $1963^{1}$ showed that the classification of neonates by birth weight percentile has a significant prognostic advantage because it improves the detection of neonates with intrauterine growth restriction (IUGR) who are at increased risk for adverse health status throughout life. ${ }^{2-4}$

The identification of pregnancies at risk for preventable perinatal handicap is a primary goal of the obstetric care provider. Pregnancies in which adverse intrauterine 
conditions result in failure of the fetus to reach its growth potential constitute such a high risk group. Next to prematurity, IUGR is the second most leading cause of perinatal mortality. ${ }^{5}$ Compared to the appropriately grown counterparts, perinatal mortality rates in growth restricted neonates are 6-10 times greater; perinatal mortality rates as high as 120 per 1000 for all cases of IUGR and 80 per 1000 after exclusion of anomalous infants have been reported. As many as 53\% of preterm still births and $26 \%$ of term still births are growth restricted. ${ }^{6}$ In survivor, the incidence of intrapartum asphysxia may be as high as $50 \%$. ${ }^{6}$ Prevention of some perinatal complications that lead to adverse outcomes in growth restricted fetus is possible with appropriate perinatal identification and management.

An important goal in contemporary obstetrics is to identify the growth restricted; fetus at risk for perinatal morbidity and mortality. Traditionally, serial sonographic evaluations of fetal biometry and amniotic fluid volume has been used along with antepartum Fetal Heart Rate (FHR) testing to assess the condition of a potentially growth restricted fetus. ${ }^{7}$

Doppler ultrasound has become available as a noninvasive technique for identifying fetal growth restriction associated with an abnormal uteroplacental and/or fetal circulation. ${ }^{8-10}$

Because a growth restricted fetus subjected to compromised blood flow is particularly at high risk for hypoxia, Doppler flow velocimetry studies have been advanced as an important technique for distinguishing the compromised small fetus from a small fetus that is unlikely to experience, serious perinatal complications. ${ }^{1}$

\section{METHODS}

The study included 50 pregnant women in third trimester suspected of IUGR $(\mathrm{n}=50)$.

\section{Type of study and duration}

i. Study design: Longitudinal

ii. Type of study: Prospective

iii. Place of study: KMC Mangalore

iv. Duration of study: Nov 2008 to March 2013

\section{Inclusion criteria}

i. Pregnant women in third trimester suspected of having IUGR

ii. Giving informed consent

iii. Reliable dates and first trimester ultrasonography

iv. High risk pregnancies (preeclampsia, anemia, heart disease etc. with the clinical manifestation of growth restriction)

v. Other medical illness complicating pregnancy

\section{Exclusion criteria}
i. Wrong dates
ii. Multiple gestation
iii. Congenital anomalies

Studies of various fetal vessels were performed using color Doppler ultrasound (GE Voluson-730 Expert, Philips-Envisor HD and GE Logic-5) curvilinear probe with a high pass filter.

The following vessels were studied with the mother in a recumbent position during fetal inactivity and apnea.

1. Umbilical Artery (UA) (Figure 1)

2. Middle Cerebral Artery (MCA) (Figure 10)

The above vessels were located in the standard plane:

The umbilical artery measurements were made from free loop of cord midway between the placental and abdominal wall insertion.

The middle cerebral artery was located in a transverse plane at the level of the lesser wing of the sphenoid bone with sample gate placed on proximal portion of the vessel.

Flow velocity wave forms, the resistance index, pulsatility index, systolic/diastolic ratio of umbilical artery, middle cerebral artery were noted.

1. Doppler study is considered abnormal when resistance and pulsatility index of umbilical artery $(>2 \mathrm{SD})$, middle cerebral artery $\left(<5^{\text {th }}\right.$ percentile, and uterine artery $(>2 \mathrm{SD})$ for the gestational age according to the standard reference values; the reference value of umbilical artery P.I. and cerebroumbilical ratio are according to Dandolo Gramellini et al. ${ }^{12}$ and MCA PI ratio \& Umbilical artery RI reference values were taken according to Kurmanavicius et al. ${ }^{11}$

2. The ratios examined were considered abnormal when PI of $\mathrm{MCA} / \mathrm{UA}<1$. $^{12}$

\section{Fetal outcome}

Fetal outcome was studied under major and minor adverse outcomes.

\section{Major adverse outcomes were}

Perinatal deaths - including intrauterine and early neonatal deaths. Major complications like hypoxic ischemic encephalopathy, intraventricular hemorrhage, periventricular leukomalacia, pulmonary hemorrhage, necrotizing enterocolitis and septicemia. 
2. Minor outcomes include-cesarean delivery for fetal distress, APGAR score below 7 at 5 minutes, admission to NICU for treatment.

The patients are followed by serial Doppler assessment and non-stress test and the results of the last Doppler examination within 10 days of delivery are considered, in the subsequent correlation with perinatal outcomes.

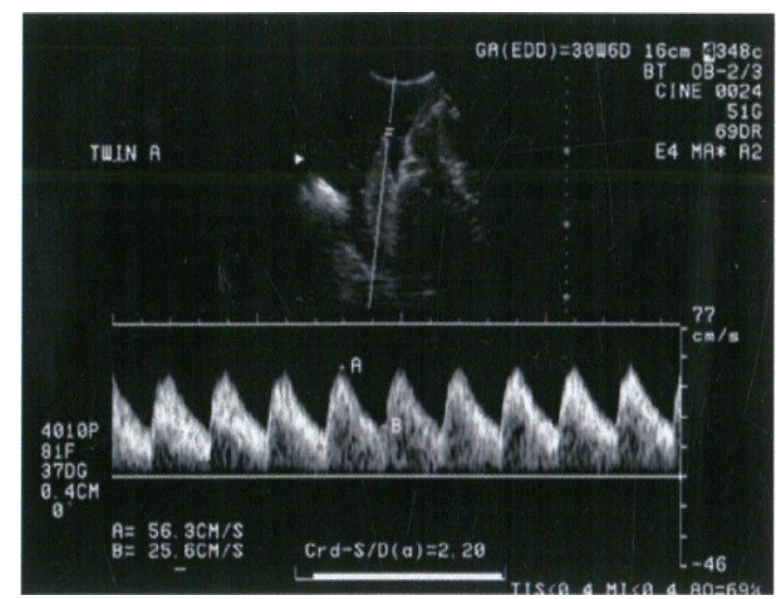

Figure 1: Normal umbilical artery waveform.

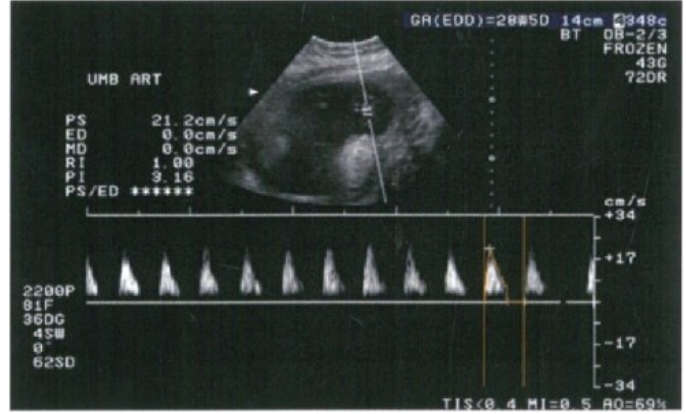

Figure 2: Umbilical artery waveform showing absent and diastolic flow.

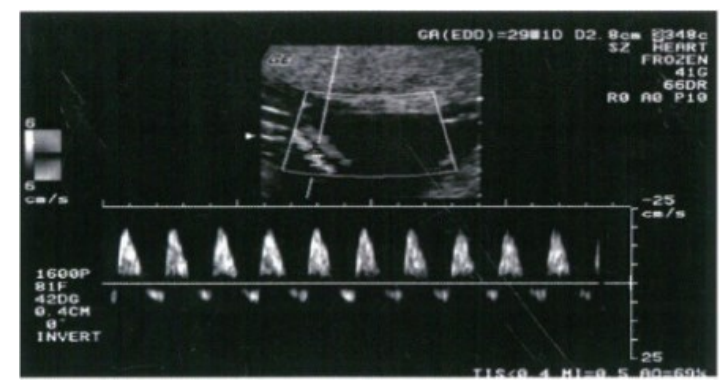

Figure 3: Waveform showing reserved and diastolic flow.
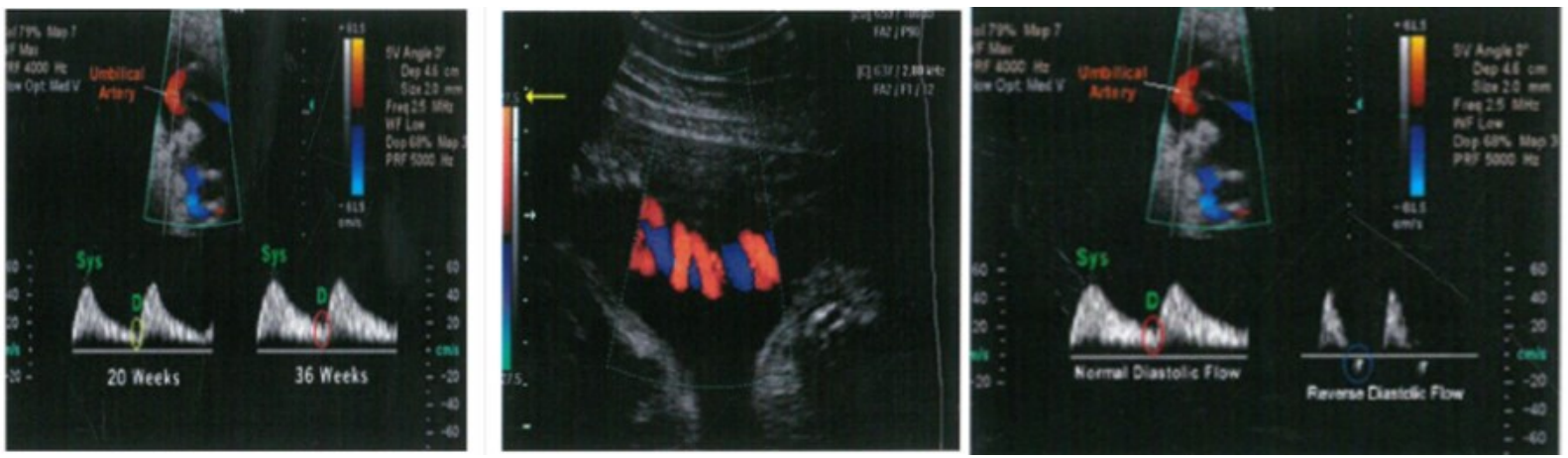

Figure 4: Umbilical artery - Doppler waveform showing and systole (Sys) diastole (D) are identified in green note that diastole is less at 20 weeks (yellow ellipse) than at 36 weeks (red ellipse).

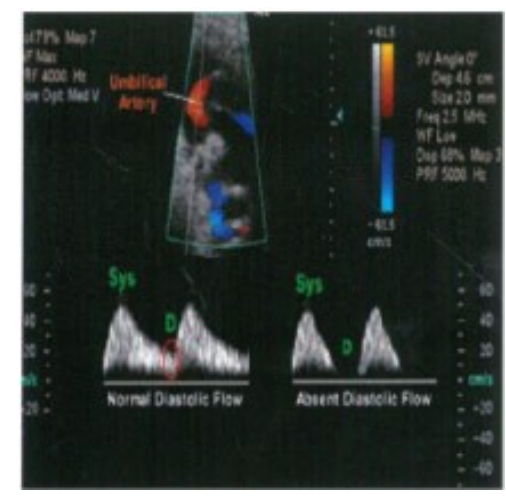

Figure 5: Umbilical artery shows absent diastolic flow and reverse diastolic flow.

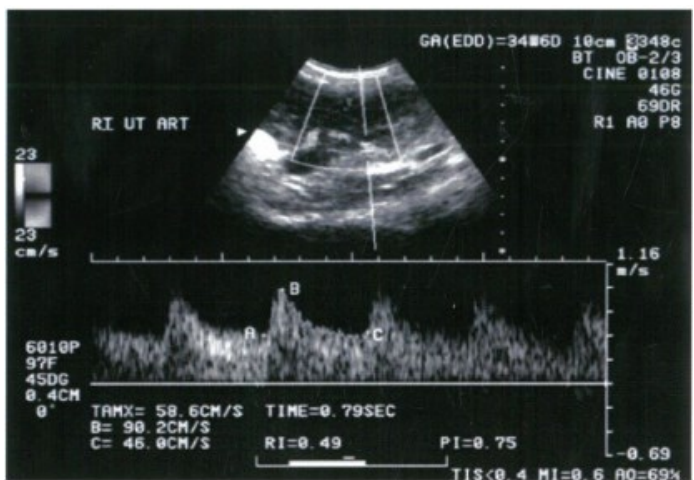

Figure 6: Normal uterine artery waveform in pregnant women. 


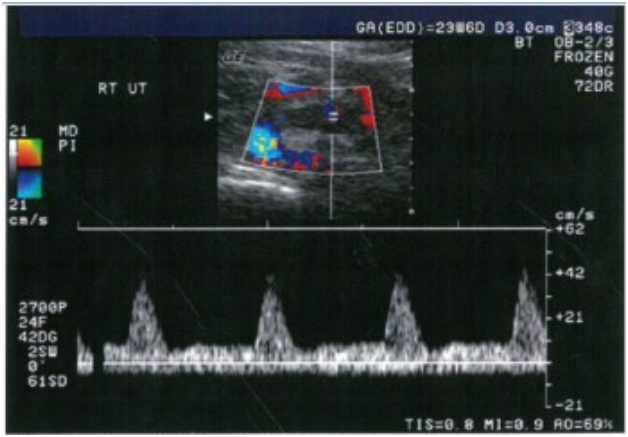

Figure 7: Abnormal uterine artery waveform.

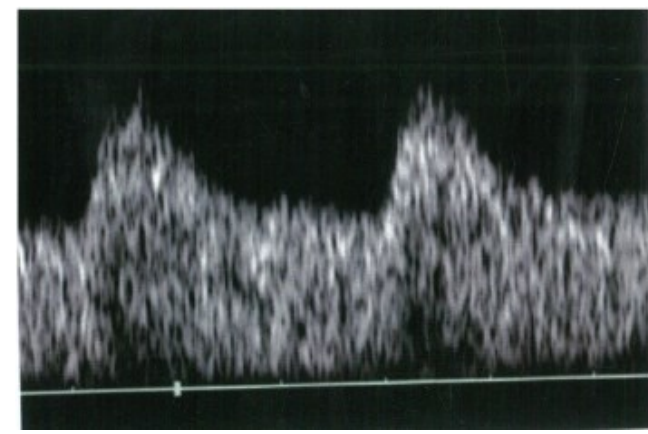

Figure 8: Normal uterine artery waveform during 24 weeks of gestation.

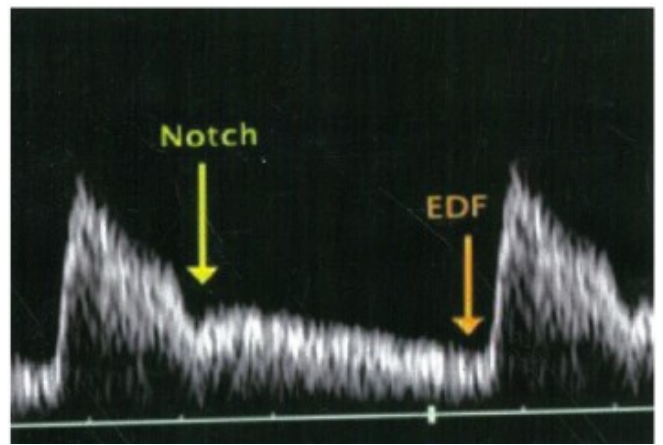

Figure 9: Waveform from the uterine artery at 24 weeks of gestation in a pregnancy with impaired placentation; in early diastole there is notch (yellow arrow) and in late diastole there is decreased flow (orange arrow).

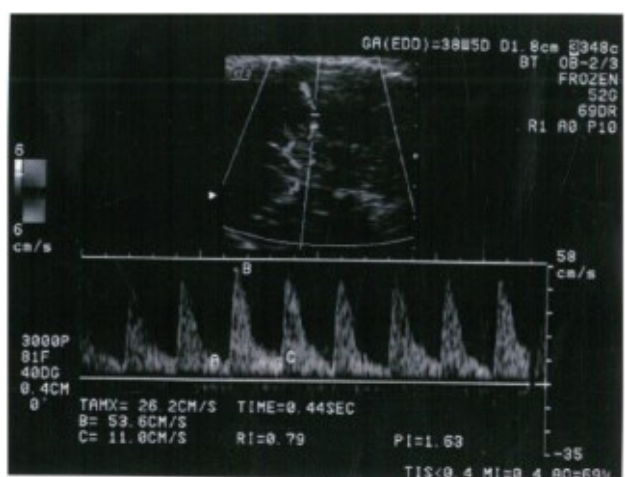

Figure 10: Normal middle cerebral artery waveform.

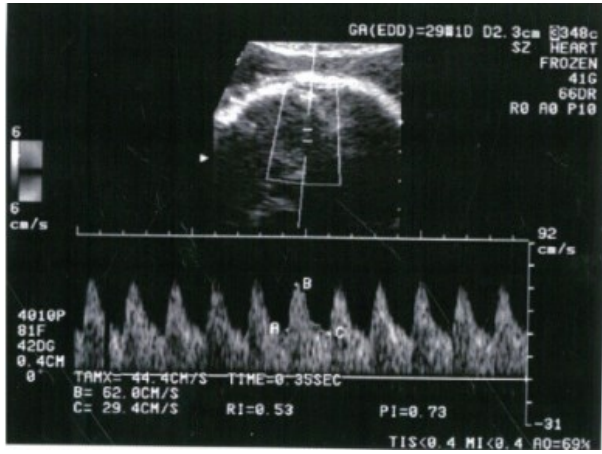

Figure 11: Abnormal middle cerebral artery waveform.

\section{RESULTS}

In our study the mean maternal age was 27.24 years. primigravidas comprised $66 \% \quad(n=33)$ of the studied population and $34 \% 9(\mathrm{n}=17)$ were multiparas. The maximum gestational age at which the delivery occurred was 32-36 weeks of gestation. Even when the parental resources were poor leading to non-affordability of NICU care, pregnancy was terminated by induction for maternal indications like severe preeclampsia.

Preeclampsia with IUGR formed the majority of the study population $(58 \%, \mathrm{n}=29)$, followed by IUGR alone $(36 \%, n=18)$, and anemia with IUGR $(6 \%, n=13)$ (Table 1).

Table 1: Patient distribution.

\begin{tabular}{|lll|}
\hline & Frequency & Percentage \\
\hline Preeclampsia with IUGR & 29 & 58.0 \\
\hline Anaemia with IUGR & 3 & 6.0 \\
\hline IUGR & 18 & 36.0 \\
\hline Total & 50 & 100.0 \\
\hline
\end{tabular}

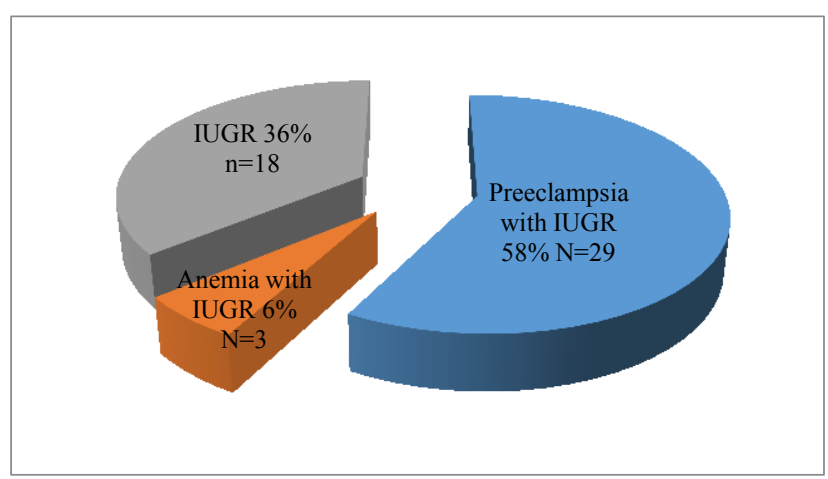

Figure 12: Patient distribution.

\section{Modes of delivery}

Out of 50 pregnancies, $10(20 \%)$ had spontaneous onset of labour and delivered. $38 \%(\mathrm{n}=18)$ induced for various reasons and $44 \%(n=22)$ were taken up for caesarean section (Table 2). 
Table 2: Modes of delivery.

\begin{tabular}{|l|l|l|}
\hline & Frequency & Percentage \\
\hline Induced & 18 & 36.0 \\
\hline LSCS & 22 & 44.0 \\
\hline Spontaneous & 10 & 20.0 \\
\hline Total & 50 & 100.0 \\
\hline
\end{tabular}

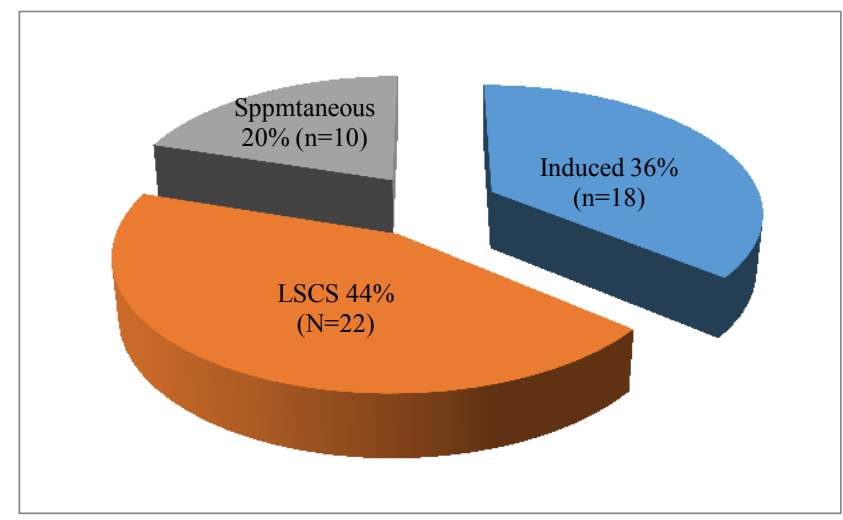

Figure 13: Modes of delivery.

\section{Incidence of meconium stained liquor}

Out of fifty pregnancies 54\% $(\mathrm{n}=27)$ had Meconium stained amniotic fluid at delivery (Figure 14).

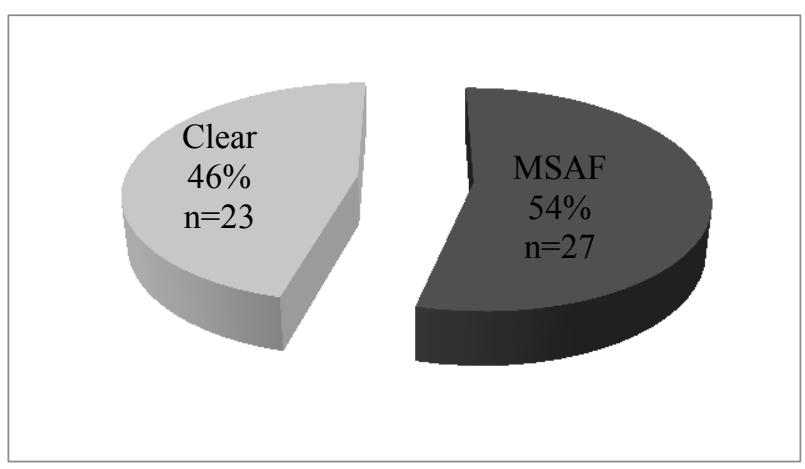

Figure 14: Meconium.

\section{Indication for $L S C S$}

Out of these 22 LSCS six were electively taken up and 16 were emergency out of which $10(45 \%)$ were done for fetal distress, $7(32 \%)$ for severe uncontrolled preeclampsia and $5(23 \%)$ for various other reasons (Table 3).

Table 3: Indication for LSCS.

\begin{tabular}{|lll|}
\hline & Frequency & Percentage \\
\hline Fetal distress & 10 & 45 \\
\hline Severe preeclampsia & 7 & 32 \\
\hline Others & 5 & 23 \\
\hline Total & 22 & 100.0 \\
\hline
\end{tabular}

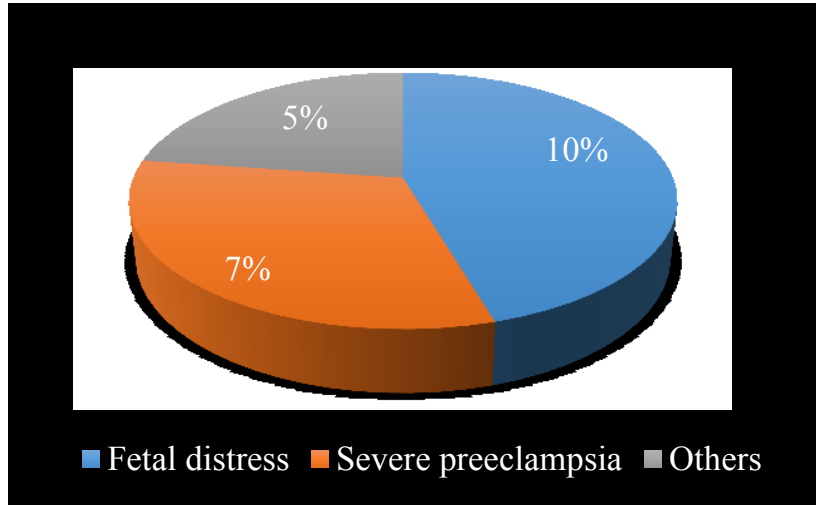

Figure 15: Indication for LSCS.

\section{Term and preterm}

There were a significant number of preterm babies in our study $(60 \%, n=30)$. This included one case of intrauterine death which was delivered at 33 weeks (Table 4).

Table 4: Term and preterm.

\begin{tabular}{|lll|} 
& Frequency & Percentage \\
\hline Preterm babies & 30 & 60.0 \\
\hline Term babies & 20 & 40.0 \\
\hline Total & 50 & 100.0 \\
\hline
\end{tabular}

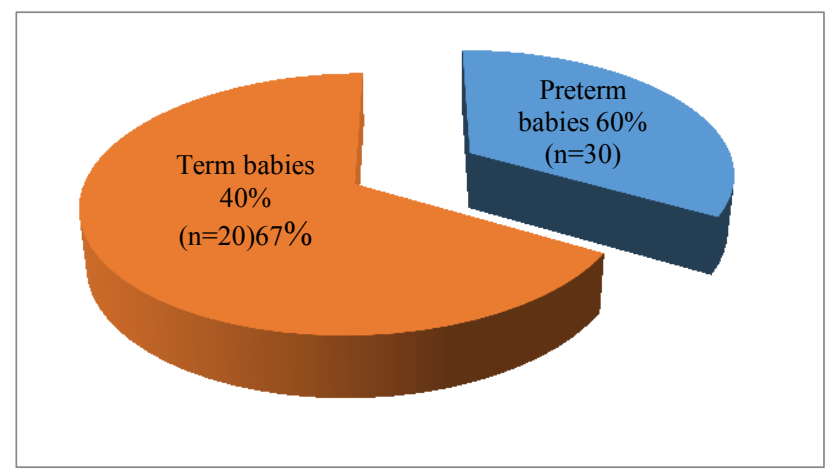

Figure 16: Term and preterm.

\section{Admission to NICU}

Out of 49 live births 37 babies were admitted in NICU for various reasons. Out of that 6 babies expired and the cause of death was septicemia and very low birth weight. Of the remaining, 21 babies required admission in NICU for more than 5 days for various reasons (Table 5).

Table 5: Admission to NICU.

\begin{tabular}{|lll|}
\hline & Frequency & Percentage \\
\hline No & 12 & 24.0 \\
\hline Yes & 37 & 76.0 \\
\hline Total & 49 & 100.0 \\
\hline
\end{tabular}




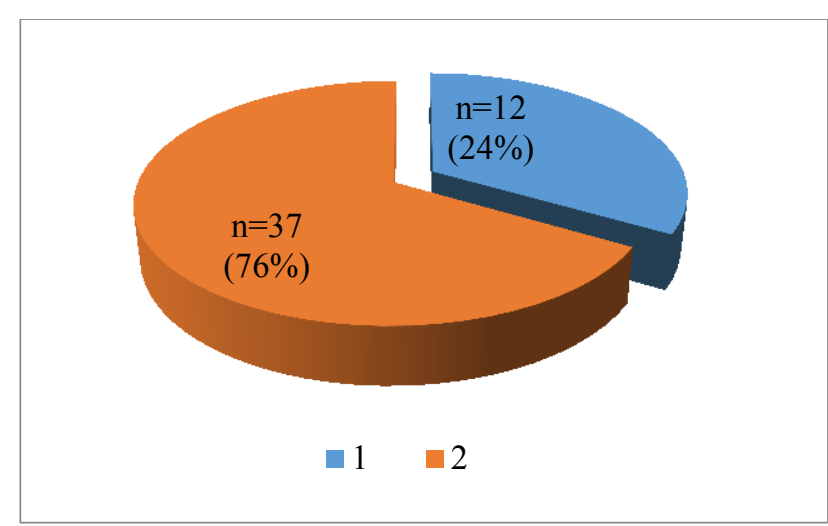

Figure 17: Admission to NICU.

\section{Neonatal complications}

Out of the 49 live births 25 babies developed some complications. The majority were septicemia $(44 \%$, $\mathrm{n}=11)$ following which was hyperbilirubinemia $(36 \%$, $n=9)$ followed by hypoglycemia $(12 \%, n=3)$. There were one each of thrombocytopenia and hypothermia. Out of all these babies which were admitted in NICU 3 babies expired of septicemia. In our study major complications like necrotizing enterocolitis (NEC) intraventricular hemorrhage (IVH), pulmonary hemorrhage and periventricular leukomalacia did not occur (Table 6).

Table 6: Neonatal complications.

\begin{tabular}{|lll|}
\hline Complication & Frequency & Percentage \\
\hline Hyperbilirubinemia & 9 & 36 \\
\hline Hypoglycemia & 3 & 12 \\
\hline Hypothermia & 1 & 4 \\
\hline Septicemia & 11 & 44 \\
\hline Thrombocytopenia & 1 & 4 \\
\hline Total & 25 & 100 \\
\hline
\end{tabular}

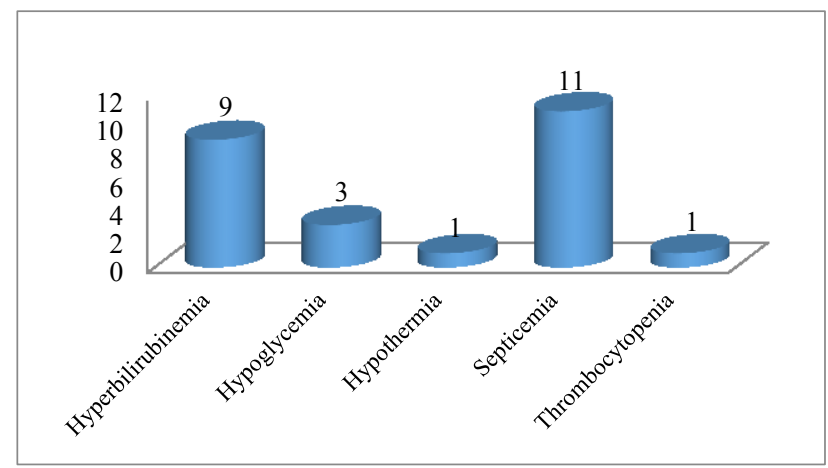

Figure 18: Neonatal complications.

\section{Birth weight distribution}

Maximum of the babies had birth weight between 1-15 $\mathrm{kg}$ at birth including one intrauterine death (IUD) which had birth weight of $1 \mathrm{~kg}$. Two babies weighed less than $1 \mathrm{kgs}$ (Table 7).
Table 7: Birth weight distribution.

\begin{tabular}{|ll|}
$\begin{array}{l}\text { Birth weight } \\
(\mathrm{kg})\end{array}$ & Frequency \\
\hline$<1$ & 2 \\
\hline $1-1.5$ & 20 \\
\hline $1.5-2$ & 13 \\
\hline $2-2.5$ & 15 \\
\hline Total & 50 \\
\hline
\end{tabular}

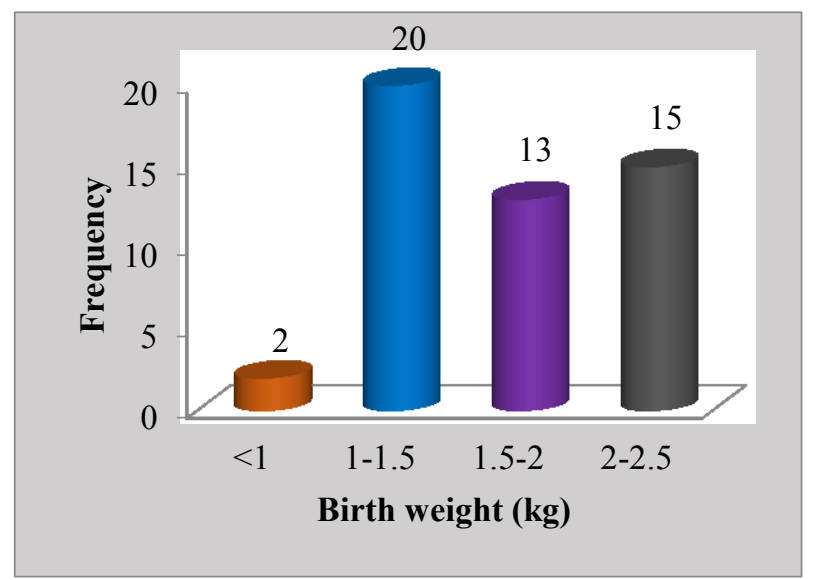

Figure 19: Birth weight distribution.

\section{APGAR at 5 minutes}

Of all the live births $(n=49) 23$ babies had APGAR at five minutes below 7 .

Table 8: APGAR at 5 minutes.

\begin{tabular}{|lll|}
\hline & Frequency & Percentage \\
\hline Abnormal $(<7)$ & 23 & 47.0 \\
\hline Normal $(\geq 7)$ & 26 & 53.0 \\
\hline Total & 49 & 100.0 \\
\hline
\end{tabular}

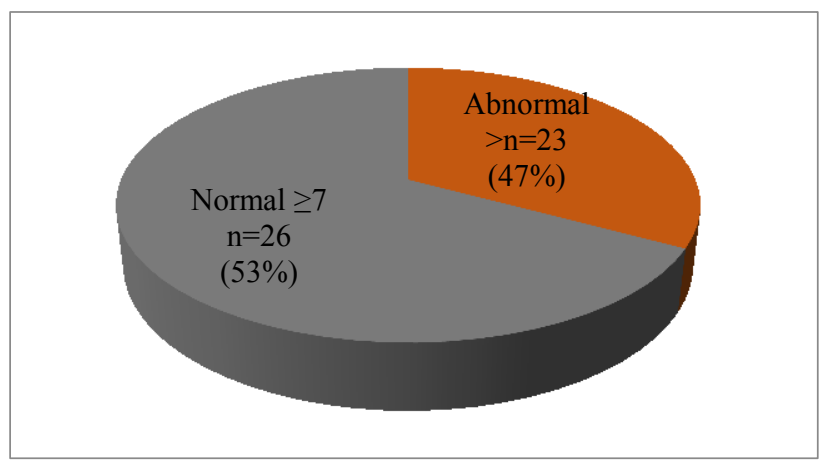

Figure 19: APGAR at 5 minutes.

\section{Perinatal outcome}

Considering the final outcome, out of fifty pregnancies one had an intrauterine death and 49 were live births. Out of these 43 babies has good outcome and were discharged 
home despite of being admitted in NICU for various reasons. During the course of treatment in NICU 6 babies had early neonatal death and septicemia accounted for 5 deaths. One of the baby who expired had only hyperbilirubinemia during the stay in NICU (Table 9).

Table 9: Perinatal outcome.

\begin{tabular}{|lll|}
\hline & Frequency & Percentage \\
\hline Early neonatal death & 6 & 12.0 \\
\hline Intrauterine fetal death & 1 & 2.0 \\
\hline Survival & 43 & 86.0 \\
\hline Total & 50 & 100.0 \\
\hline
\end{tabular}

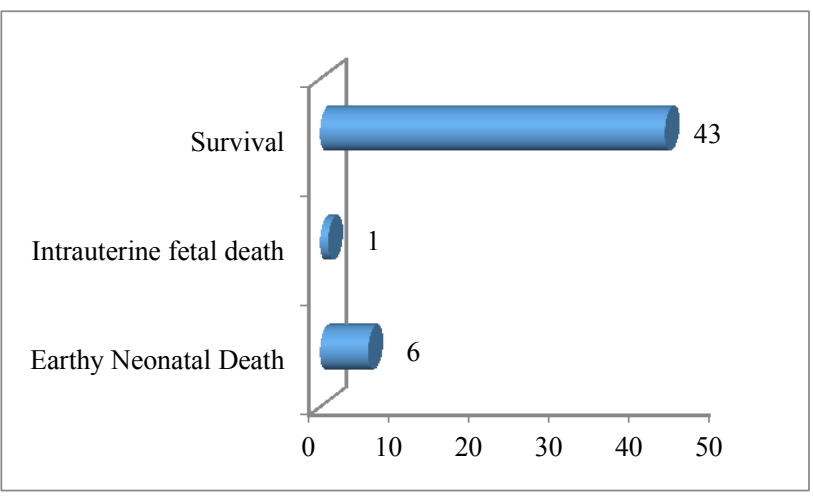

Figure 20: Perinatal outcome.

Umbilical artery RI in prediction of major and minor outcome

Sensitivity: $60.15 \%$

Specificity: $76.66 \%$

Positive predictive value: $63.15 \%$

Negative predictive value: $74.19 \%$

Diagnostic accuracy: $74 \%$

Table 10: Umbilical artery RI in prediction of major and minor outcome.

\begin{tabular}{|llll|}
\hline $\begin{array}{l}\text { Umbilical } \\
\text { artery RI }\end{array}$ & \multicolumn{2}{l}{$\begin{array}{l}\text { Perinatal outcome } \\
\text { (major and minor) }\end{array}$} \\
& Present & Absent & Total \\
\hline Abnormal & 12 & 7 & 19 \\
\hline Normal & 8 & 23 & 31 \\
\hline Total & 20 & 30 & 50 \\
\hline
\end{tabular}

\section{Umbilical artery PI in prediction of major and minor outcome}

Sensitivity: $55 \%$

Specificity: $86.66 \%$
Positive predictive value: $73.33 \%$

Negative predictive value: $74.28 \%$

Diagnostic accuracy: 74\%

Table 11: Umbilical artery PI in prediction of major and minor outcome.

\begin{tabular}{|llll|}
\hline $\begin{array}{l}\text { Umbilical } \\
\text { artery PI }\end{array}$ & \multicolumn{2}{l}{$\begin{array}{l}\text { Perinatal outcome } \\
\text { (major and minor) }\end{array}$} \\
\cline { 2 - 4 } & Present & Absent & Total \\
\hline Abnormal & 11 & 4 & 15 \\
\hline Normal & 9 & 26 & 35 \\
\hline Total & 20 & 30 & 50 \\
\hline
\end{tabular}

\section{Abnormal umbilical artery $R I$ in prediction of major and minor outcome}

Sensitivity: $80 \%$

Specificity: $86.66 \%$

Positive predictive value: $80 \%$

Negative predictive value: $86.6 \%$

Diagnostic accuracy: $84 \%$

Table 12: Abnormal umbilical artery RI in prediction of major and minor outcome.

\begin{tabular}{|c|c|c|c|}
\hline \multirow{2}{*}{$\begin{array}{l}\text { Umbilical } \\
\text { artery } \\
\text { waveform }\end{array}$} & \multicolumn{3}{|c|}{$\begin{array}{l}\text { Perinatal outcome } \\
\text { (major and minor) }\end{array}$} \\
\hline & Present & Absent & Total \\
\hline Abnormal & 16 & 4 & 20 \\
\hline Normal & 4 & 26 & 30 \\
\hline Total & 20 & 30 & 50 \\
\hline
\end{tabular}

\section{Abnormal umbilical artery waveforms (Figure 5)}

- $\quad$ Raised S/D ratio:14

- Absent diastolic flow: 2 (Figure 2)

- $\quad$ Reversed end diastolic flow: 4 (Figure 3)

$>$ Out of the 14 raised S/D ratio flow 8 had major adverse outcome that included 5 cases of septicemia and three cases of early neonatal death

$>$ Out of the two absent diastolic flow-emergency LSCS was done for non-reactive NST for one case. Though the baby had suffered septicemia it recovered and survived. But the other one for whom an elective LSCS was done the baby succumbed to death though the baby only had suffered from hyperbilirubinemia during the stay at NICU 
$>$ Of the four reversed end diastolic flow:

One had intrauterine fetal death, one was taken up for elective LSCS and the baby had good outcome, one baby expired on the $1^{\text {st }}$ postnatal day, and though one baby had severe sepsis finally survived

$>$ In study 6 cases of absent/reversed end diastolic flow were seen and out of that one was intrauterine death, two had early neonatal death and three had good outcome though they had suffered severe sepsis. Probably due to early intervention. This suggests that absent or reversed end diastolic flow is the independent parameter in the prediction of adverse perinatal outcome.

\section{MCA PI in prediction of major and minor perinatal outcome}

Sensitivity: $90 \%$

Specificity: $93.3 \%$

Positive predictive value: $90 \%$

Negative predictive value: $93.3 \%$

Diagnostic accuracy: 92\%

Table 13: MCA PI in prediction of major and minor perinatal outcome.

\begin{tabular}{|llll|}
\hline MCA PI & \multicolumn{3}{l}{$\begin{array}{l}\text { Perinatal outcome } \\
\text { (major and minor) }\end{array}$} \\
& Present & Absent & Total \\
\hline Abnormal & 18 & 2 & 20 \\
\hline Normal & 2 & 28 & 30 \\
\hline Total & 20 & 30 & 50 \\
\hline
\end{tabular}

\section{MCA/UA PI in prediction of major and minor outcome}

Sensitivity: $75 \%$

Specificity: $96.6 \%$

Positive predictive value: $93.7 \%$

Negative predictive value: $85.2 \%$

Diagnostic accuracy: $88 \%$

\section{Umbilical artery $R I$ in prediction of major outcome}

Sensitivity: $66.6 \%$

Specificity: $74 \%$

Positive predictive value: $52 \%$
Negative predictive value: $83.8 \%$

Table 14: MCA/UA PI in prediction of major and minor outcome.

\begin{tabular}{|llll|}
\hline MCA/UA & \multicolumn{3}{l}{$\begin{array}{l}\text { Perinatal outcome } \\
\text { (major and minor) }\end{array}$} \\
\hline PI & Present & Absent & Total \\
\hline Abnormal & 15 & 1 & 16 \\
\hline Normal & 2 & 29 & 34 \\
\hline Total & 20 & 30 & 50 \\
\hline
\end{tabular}

Table 15: Umbilical artery RI in prediction of major outcome.

\begin{tabular}{|llll|}
$\begin{array}{l}\text { Umbilical } \\
\text { artery RI }\end{array}$ & Perinatal outcome (major) \\
\hline Abnormal & 10 & 9 & 19 \\
\hline Normal & 5 & 26 & 31 \\
\hline Total & 15 & 35 & 50 \\
\hline
\end{tabular}

\section{Umbilical artery PI in prediction of major outcome}

Sensitivity: $66.66 \%$

Specificity: $85.71 \%$

Positive predictive value: $66.66 \%$

Negative predictive value: $85.71 \%$

Diagnostic accuracy: $80 \%$

Table 16: Umbilical artery RI in prediction of major outcome.

\begin{tabular}{|llll|}
$\begin{array}{l}\text { Umbilical } \\
\text { artery PI }\end{array}$ & Perinatal outcome (major) \\
\hline Abnormal & 10 & 9 & 19 \\
\hline Normal & 5 & 26 & 31 \\
\hline Total & 15 & 35 & 50 \\
\hline
\end{tabular}

Abnormal umbilical artery waveforms in prediction of major outcome

Sensitivity: $80 \%$

Specificity: $77 \%$

Positive predictive value: $60 \%$

Negative predictive value: $90 \%$

Diagnostic accuracy: 78\%

MCA PI in prediction of major outcome

Sensitivity: $65 \%$ 
Specificity: $80.5 \%$

Positive predictive value: $65 \%$

Negative predictive value: $93.3 \%$

Diagnostic accuracy: $82 \%$

Table 17: Abnormal umbilical artery waveforms in prediction of major outcome.

\begin{tabular}{|c|c|c|c|}
\hline \multirow{2}{*}{$\begin{array}{l}\text { Umbilical } \\
\text { artery } \\
\text { waveforms }\end{array}$} & \multicolumn{3}{|c|}{ Perinatal outcome (major) } \\
\hline & Present & Absent & Total \\
\hline Abnormal & 12 & 8 & 20 \\
\hline Normal & 3 & 27 & 30 \\
\hline
\end{tabular}

Table 18: MCA PI in prediction of major outcome.

\begin{tabular}{|llll|}
\hline \multirow{2}{*}{ MCA PI } & \multicolumn{2}{l}{ Perinatal outcome (major) } \\
\hline Abnormal & Present & Absent & Total \\
\hline Normal & 2 & 7 & 20 \\
\hline Total & 15 & 28 & 30 \\
\hline
\end{tabular}

\section{MCA/UA PI in prediction of major outcome}

Sensitivity: $86.6 \%$

Specificity: $91.4 \%$

Positive predictive value: $81.2 \%$

Negative predictive value: $94.1 \%$

Diagnostic accuracy: 90\%
Table 19: MCA/UA PI in prediction of major outcome.

\begin{tabular}{|llll|}
\hline MCA/UA & \multicolumn{2}{c}{ Perinatal outcome (major) } \\
\hline PI & Present & Absent & Total \\
\hline Abnormal & 13 & 3 & 16 \\
\hline Normal & 2 & 32 & 34 \\
\hline Total & 15 & 35 & 50 \\
\hline
\end{tabular}

\section{Doppler indices in prediction of adverse perinatal outcome}

The Table 20 depicts the efficacy of various Doppler parameters in prediction of adverse perinatal outcome. Statistical analysis shows that MCA PI is the most sensitive parameter in the prediction of adverse perinatal outcome (90\%), specificity being the highest for MCA/UAPI (96.6\%). Positive predictive value is highest for MCA/UA PI $(93.7 \%)$ and the negative predictive value highest being for the MCA PI (93.3\%).

Table 20: Doppler indices in prediction of adverse perinatal outcome.

\begin{tabular}{|lllll|}
\hline & Sensitivity & Specificity & PPV & NPV \\
\hline Umbilical A RI & 60.1 & 76.6 & 63.1 & 74.1 \\
\hline Umbilical A PI & 55 & 86.6 & 73.3 & 74.2 \\
\hline Umbilical A S/D & 80 & 86.6 & 80 & 86.6 \\
\hline MCA PI & 90 & 93.3 & 90 & 93.3 \\
\hline PIMCA/UA & 75 & 96.6 & 93.7 & 85.2 \\
\hline
\end{tabular}

Efficacy of Doppler in predicting adverse perinatal outcome (major)

The Table 21 depicts the comparison of our study with the study by BN Lakhhar et al. for various parameters to predict the major perinatal outcome.

Table 21: Efficacy of Doppler in predicting adverse perinatal outcome (major).

\begin{tabular}{|llllllllll|}
\hline & \multicolumn{2}{l}{ Sensitivity $(\%)$} & \multicolumn{2}{l}{ Specificity $(\%)$} & PPV $(\%)$ & \multicolumn{2}{l|}{ NPV $(\%)$} \\
& BNL & Present & BNL & Present & BNL & Present & BNL & Present \\
\hline UARI & 58 & 66.6 & 71.7 & 74 & 35 & 52 & 86.8 & 83.8 \\
\hline UAPI & 58 & 66.6 & 56.5 & 85.71 & 35 & 66.6 & 86.8 & 85.71 \\
\hline UA S/D & 75 & 80 & 41.3 & 77.1 & 25 & 60 & 86.8 & 90 \\
\hline MCA PI & 66.6 & 65 & 71.7 & 80.5 & 47 & 65 & 90 & 93.5 \\
\hline MCA/UAPI & 66.6 & 86.6 & 73.9 & 91.4 & 40 & 81.2 & 89.4 & 94.1 \\
\hline
\end{tabular}

UA-Umbilical artery, MCA-Middle cerebral artery, RI-Resistive index, PI-Pulsatility index, S/D-Systolic/diastolic ratio

MCA/UA PI was the most sensitive (86.6\%), most specific $(91.4 \%)$, with highest positive predictive value $(81.2 \%)$ and negative predictive value $(94.1 \%)$ in prediction of major perinatal outcome which was comparable to the study by BN Lakhhar et al. where sensitivity was highest for MCA/UA PI (66.6\%) and with highest specificity $(73.9 \%)$.

\section{Efficacy of PI in predicting adverse perinatal outcome} (major \& minor)

In considering Pulsatility Index (PI) for prediction of major and minor adverse outcome sensitivity was highest for MCA PI $(90 \%)$ whereas in a study by Dandolo Gram et al it was for MCA/UA PI (68\%) and in a study by BN 
Lakhhar et al. it was for UA PI (50\%). In our study specificity came highest for MCA/UA LPI (96.6\%) in contrast to study by Dandolo Gram et al. and B. N.
Lakhhar et al. where the specificity was highest for MCA PI (100\%) and 90.9\% respectively.

Table 22: Efficacy of PI in predicting adverse perinatal outcome (major \& minor).

\begin{tabular}{|lllllllllllll|}
\hline & \multicolumn{3}{c}{ Sensitivity $(\%)$} & \multicolumn{2}{c}{ Specificity $(\%)$} & \multicolumn{2}{c}{ PPV $(\%)$} & \multicolumn{3}{c|}{ NPV $(\%)$} \\
\hline MCA & A & B & P & A & B & P & A & B & P & A & B & P \\
\hline UA & 24 & 41.6 & 90 & 100 & 90.9 & 93.3 & 100 & 88.2 & 90 & 77.3 & 48.7 & 93.3 \\
\hline MCA/UA & 64 & 50 & 55 & 90.7 & 59 & 86.6 & 72.7 & 66.6 & 73.3 & 86.7 & 45.4 & 74.2 \\
\hline
\end{tabular}

A - Dandologarm et al., B - B. N. Lakhhar et al., P - Present study

\section{Efficacy of PI in predicting adverse perinatal outcome (major)}

In considering Pulsatility Index (PI) for prediction of major and minor adverse outcome sensitivity was highest for MCA PI $(90 \%)$ whereas in a study by Dandolo Gram et al it was for MCA/UA PI (68\%) and in a study by BN Lakhhar et al. it was for UA PI $(50 \%)$. In our study specificity came highest for MCA/UA LPI (96.6\%) in contrast to study by Dandolo Gram et al. and B. N. Lakhhar et al where the specificity was highest for MCA PI $(100 \%)$ and $90.9 \%$ respectively.

Considering the pulsatility indices of various arteries in prediction of major perinatal outcome MCA/UA PI had the highest sensitivity $(86.6 \%)$ which was comparable to study by B. N. Lakhhar et al. (66.6\%). The positive predictive value was highest for MCA PI (73.9\%) but in a study by Kath Fong et al it was for UA PI $(81.8 \%)$.

Table 23: Efficacy of PI in predicting adverse perinatal outcome (major).

\begin{tabular}{|llllllllllll|l|} 
& \multicolumn{3}{c}{ Sensitivity $(\%)$} & \multicolumn{3}{c}{ Specificity $(\%)$} & \multicolumn{1}{c}{ PPV $(\%)$} & \multicolumn{3}{c|}{ NPV $(\%)$} \\
& A & B & P & A & B & P & A & B & P & A & B & P \\
\hline MCA & 66.6 & 91.7 & 65 & 71.7 & 53.9 & 80.5 & 47 & 15.1 & 65 & 90 & 98.6 & 93.3 \\
\hline UA & 58 & 58.3 & 66.6 & 56.5 & 81.8 & 85.7 & 35 & 22.2 & 66.6 & 86.8 & 95.7 & 85.7 \\
\hline MCA/UA & 66.6 & 62.5 & 86.6 & 73.9 & 75.5 & 91.4 & 40 & 18.5 & 81.2 & 89.4 & 95.8 & 94.1 \\
\hline
\end{tabular}

A - B. N. Lakhhar et al., B - Kath W. Fong et al., P - Present study

\section{Abnormal $U A$ waveforms in predicting adverse perinatal outcome (major).}

Table 24 depicts the diagnostic accuracy of abnormal umbilical artery waveforms in prediction of major perinataloutcome. Our study yielded the sensitivity of $80 \%$ which is comparable to study by Schulman et al and B. N. Lakhhar et al.

Table 24: Abnormal UA waveforms in predicting adverse perinatal outcome (major).

\begin{tabular}{|lllll|}
\hline $\begin{array}{l}\text { Study } \\
\begin{array}{l}\text { Schulman } \\
\text { et al. }\end{array}\end{array}$ & 65 & 91 & 43 & 96 \\
\hline $\begin{array}{l}\text { Lakhhar } \\
\text { BN et al. }\end{array}$ & 75 & 41.3825286 .3 & 90 & \\
\hline $\begin{array}{l}\text { Present } \\
\text { study }\end{array}$ & 80 & 77.1 & 60 & 90 \\
\hline
\end{tabular}

Diagnostic accuracy of various parameters in prediction of adverse perinatal outcome

From our study it was found that the diagnostic accuracy was highest for MCA PI (92\%) in prediction of overall adverse outcome whereas MCA PI (90\%) had the most diagnostic accuracy for the prediction of major adverse outcome.

Table 25: Diagnostic accuracy of various parameters in prediction of adverse perinatal outcome.

\begin{tabular}{|lll|}
\hline Parameters & $\begin{array}{l}\text { Diagnostic } \\
\text { accuracy major } \\
\text { and minor }(\%)\end{array}$ & $\begin{array}{l}\text { Diagnostic } \\
\text { accuracy } \\
\text { major (\%) }\end{array}$ \\
\hline UA RI & 74 & 72 \\
\hline UA PI & 74 & 80 \\
\hline UA S/D & 84 & 78 \\
\hline MCA PI & 92 & 82 \\
\hline MCA/UA PI & 88 & 90 \\
\hline
\end{tabular}




\section{Diagnostic accuracy of various PI in prediction of adverse perinatal outcome}

The Table 26 shows the diagnostic accuracy of various PI in prediction of overall perinatal outcome. MCA/UA PI had the highest diagnostic accuracy (90\%) which was comparable to the study by Gramellini et al. (90\%). It shows that the diagnostic accuracy of the MCA/UA PI ratio is better predictor of adverse outcome than PI of each alone.

Table 26: Diagnostic accuracy of various PI in prediction of adverse perinatal outcome.

\begin{tabular}{|llll|}
\hline Study & $\begin{array}{l}\text { UA PI } \\
(\%)\end{array}$ & $\begin{array}{l}\text { MCA PI } \\
(\%)\end{array}$ & $\begin{array}{l}\text { MCA/UA PI } \\
(\%)\end{array}$ \\
\hline A & 83.3 & 78.8 & 90 \\
\hline B & 80 & 82 & 90 \\
\hline
\end{tabular}

A - Gramellini et al., B - Present study

\section{UA PI for prediction of major \& minor outcome}

The Table 27 shows the UA PI prediction of adverse perinatal outcome, the sensitivity being $56 \%$ which is comparable to study by KF et al. and B. N. Lakhhar et al. (44.7\% and 50\% respectively).

Table 27: UA PI for prediction of major \& minor outcome.

\begin{tabular}{|lll|}
\hline Study & $\begin{array}{l}\text { Sensitivity } \\
(\%)\end{array}$ & $\begin{array}{l}\text { Specificity } \\
(\%)\end{array}$ \\
\hline KF et al. & 44.7 & 86.6 \\
\hline B. N. Lakhhar et al. & 50 & 59 \\
\hline Present study & 56 & 52 \\
\hline
\end{tabular}

\section{DISCUSSION}

In normal pregnancy, as the gestation advances the three indices namely, the S/D ratio, the Pulsatility Index (PI) and the Resistive Index (RI), decrease in umbilical artery. But, in IUGR, first there is decrease in diastolic flow in the umbilical artery due to increase in the resistance of small arteries and arterioles of the tertiary villi. This raises the S/D ratio, PI and the RI of the umbilical artery. As the placental insufficiency worsens, the diastolic flow decreases, becomes absent and later reverses. In milder form of placental insufficiency, the decrease in diastolic velocity remains constant even with advancing gestation. The prevalence of perinatal death in fetuses with absent/reversed end diastolic flow velocity is reported to be over $40 \%{ }^{14}$ In our study it is found to be $50 \%$ Yoon et al. ${ }^{15}$ demonstrated in their study that absent umbilical artery waveform is a strong and independent predictor of adverse perinatal outcome.

As already described, fetal middle cerebral artery (MCA) is a low resistance circulation throughout pregnancy and accounts for $7 \%$ of total fetal cardiac output. ${ }^{16}$
MCA reacts earlier and more sensitively than Common Carotid Artery (CCA) to hypoxia and ischemia. ${ }^{17}$ The MCA impedance varies during gestation according to Mari et $a l,{ }^{13}$ with a parabolic pattern during pregnancy and does not change significantly after delivery.

Increase in diastolic flow with decreased pulsatility index shows the brain sparing effect taking place in compromised fetuses. Arbeille et al. ${ }^{12}$ found that the cerebroplacentan ratio is constant during pregnancy especially after 30 weeks and suggested one as the cut off value; all values less than one are considered abnormal. This ratio shown to have higher sensitivity $(86.6 \%)$ when compared with PI of MCA alone $(65 \%)$, which is comparable to the study by B. N. Lakhhar et al. (66.6\%).

In the analysis of adverse perinatal outcome including both major and minor, MCA PI had the highest sensitivity $(90 \%)$ in contrast to study by Dandolo Gram et al. which had highest sensitivity for MCA/UA PI $(68 \%)$ and to the study by B. N. Lakhhar et al. which had highest sensitivity for UA PI (50\%). In our study, specificity and positive predictive value were highest for MCA/UA PI (96.6\% and $93.7 \%$ respectively) and the negative predictive value being highest for MCA PI $(93.3 \%)$.

We found that ratio of $\mathrm{PI}$ of $\mathrm{MCA} / \mathrm{UA}$ is more sensitive $(86.6 \%)$ than MCA PI alone $(65 \%)$ in predicting major adverse neonatal outcome in contrast to study by Fong et al (1999), which had shown sensitivity of $91.7 \%$ for MCA PI alone than that for MCA/UA PI (62.5\%). Our study is comparable to study by B. N. Lakhhar et al. which showed similar results.

In a study by K. W. Fong et al. (1999), it was concluded that a normal MCA PI is helpful to identify the fetuses without a major adverse perinatal outcome, hence once the umbilical artery PI is abnormal, it is better to perform the MCA PI to know the extent of brain sparing, stressing the importance of studying two vessels in the Doppler had shown sensitivity of $91.7 \%$ for MCA PI alone than that for MCA/UA PI (62.5\%). Our study is comparable to study by Lakhhar BN et al. which showed similar results.

In a study by K. W. Fong et al. (1999), it was concluded that a normal MCA PI is helpful to identify the fetuses without a major adverse perinatal outcome, hence once the umbilical artery PI is abnormal, it is better to perform the MCA PI to know the extent of brain sparing, stressing the importance of studying two vessels in the Doppler.

Our study was concurring with most of the findings done in earlier studies hence emphasizing the role of Doppler in predicting adverse perinatal outcome.

\section{ACKNOWLEDGEMENTS}

We would like to thank Manipal University, Kasturba medical college, departments of obstetrics \& gynecolgy and radiodiagnosis. 
Funding: No funding sources

Conflict of interest: None declared

Ethical approval: Not required since it was done as a routine protocol for antenatal ultrasound on patients in $O P D \&$ hospital admissions

\section{REFERENCES}

1. Giampaolo Mandruzzato, Aris Antsaklis, Francesc Botet, Frank A. Chervenak, Francisc Figueras, Amos Grunebaum, et al. Intrauterine restriction (IUGR). J Perinat Med. 2008;36(4):277-81.

2. Adre J. du Plessis. Cerebral blood flow and metabolism in the developing fetus. Clin Perinatol. 2009:36(3):531-48.

3. Scifres CM, Stamilio D, Macones GA, Odibo AO. Predicting perinatal mortality in preterm intrauterine growth restriction. Am J Perinatal. 2009;26(10):7238 .

4. Kingdom JC, Burrell SJ, Kaufmann P. Pathology and clinical implications of abnormal umbilical artery Doppler waveforms. Ultrasound Obstet Gynecol. 1997;9(4):271-86.

5. Wolfe HM, Gross TL, Sokol RJ. Recurrent small for gestational age birth: perinatal risks and outcomes. Am J Obstet Gynecol. 1987;157(2):288-93.

6. Gardosi J, Mul T, Mongelli M, Fagan D. Analysis of birth weight and gestational age in antepartum stillbirths. Br J Obstet Gynecol. 1998;105(5):524-30.

7. Seeds JW. Impaired fetal growth: ultrasonic evaluation and clinical management. Obstet Gynecol. 1984;64(4):577-84.

8. Trudinger BJ, Giles WB, Cook CM. Flow velocity waveforms in the maternal uteroplacental and fetal umbilical circulations. Am J Obstet Gynecol. 1985;152(2):155-63.

9. 9.Fleischer A, Schulman H, Farmakides G, Bracero L, Blattner P, Randolph G. Umbilical artery velocity waveforms and intrauterine growth retardation. Am J Obstet Gynecol. 1985;151(4):502-5.

10. Campbello S, Diaz-Recasens J, Griffin DR, CohenOverbeek TE, Pearce JN, Willson K, et al. New
Doppler technique for assessing utero placental blood flow. Lancet. 1983;321(8326):675-7.

11. Kurmanavicius J, Florio I, Wisser J, Hebisch G, Zimmermann R, Müller R, et al. Reference resistance indices of the umbilical, fetal middle cerebral and uterine arteries at 24-42 weeks of gestation. Ultrasound Obstet Gynecol. 1997;10(2):112-20.

12. .Gramellini D, Folli MC. Cerebral-umbilical Doppler ratio as a predictor of adverse perinatal outcome. Obstet Gynecol. 1992;79:416-20.

13. Mari G, Deter RL. Middle cerebral artery flow velocity waveforms in normal and small-forgestational-age fetuses. Am J Obstet Gynecol. 1992;166:1262-70.

14. Madazli R. Prognostic factors for survival of growthrestricted fetuses with absent end-diastolic velocity in the umbilical artery. J Perinatol. 2002 Jun;22(4):286-90.

15. Yoon BH, Lee CM, Kim SW. An abnormal umbilical artery waveform; a strong and independent predictor of adverse perinatal outcome in patients with preeclampsia. Am J Obstet Gynecol. 1994;171:713-21.

16. Giles WB. Vascular Doppler techniques. Obstet Gynecol Clin North Am. 1999 Dec;26(4):595-606, vi.

17. Meyberg GC, Solomayer EF, Grishke EM, Bastert G. Does the measurement of four fetal arteries provide more information than the measurement of just two arteries in perinatal Doppler sonography? Ultrasound Obstet Gynecol. 1999;13:407-14.

18. Lakhkar BN, Rajagopal KV, Gourisankar PT. Doppler prediction of adverse perinatal outcome in $\mathrm{PIH}$ and IUGR. Indian $\mathrm{J}$ Radiol Imaging. 2006;16:109-16.

DOI: $10.5455 / 2320-1770 . i j r \operatorname{cog} 20150223$

Cite this article as: Mahale N, Khanal B, Mahale A, Fernandes M, Rao P, Chavadi C. Doppler prediction of adverse perinatal outcome in intrauterine growth restriction. Int J Reprod Contracept Obstet Gynecol 2015;4:119-30. 